\title{
Gas Pool Coupled Activating TIG Welding Method with Coupling Arc Electrode
}

\author{
Yong Huang ${ }^{1 *}$, Rui-Lin Liu² and Yan-Zhao Hao ${ }^{3}$
}

\begin{abstract}
Gas pool coupled activating TIG (GPCA-TIG) welding put forward in-house can dramatically enhance weld penetration of TIG welding through introducing active element oxygen to reverse the Marangoni convection flow in the molten pool. In order to further improve the welding productivity, the normal solid tungsten electrode is replaced by a kind of coupling arc electrode. The changes of arc pressure distribution along anode surface and the weld appearance were evaluated. On this basis, the dependences of weld shape characterized with weld depth, width and undercut on the main welding parameters were discussed. The results indicate, the substitution of coupling arc electrode can lead to an obvious decrease of arc pressure. Compared to hollow tungsten electrode and twin tungsten electrodes, the coupling arc electrode is much easier to manufacture and has more compacter structure. Combined with the symmetric distribution of arc pressure in different directions, this electrode has extensive adaptability. In the GPCA-TIG welding with coupling arc electrode, both the substitution of coupling arc electrode and the introduction of outer active gas oxygen can reduce the possibilities of producing humping bead and undercut. Their joint action makes this welding method have the capability of realizing high travel speed and deep penetration welding.
\end{abstract}

Keywords: GPCA-TIG welding, Coupling arc electrode, Oxygen, Arc pressure, Weld shape, Welding parameter

\section{Introduction}

High welding production is one of the desirable objectives to pursuit for more and more manufacturing enterprises and welding research institutes. Especially for the Tungsten Inert Gas welding, it is well-known for its high welding quality among the common welding methods due to the inert shielding gas and the non-melting tungsten electrode. Because of the low current allowable value to prevent tungsten electrode from melting and the phenomenon of arc divergence resulting from the low heat conductivity of argon shielding gas, however, low welding productivity has become its biggest shortcoming. It is believed that, improving the welding production by combination of high welding speed and deep weld depth can greatly broaden the application field of TIG welding.

Increasing welding speed must eliminate several weld forming defects, such as undercut and humping bead.

\footnotetext{
*Correspondence: hyorhot@lut.cn

${ }^{1}$ State Key Laboratory of Advanced Processing and Recycling of Non-ferrous Metals, Lanzhou University of Technology, Lanzhou 730050, China

Full list of author information is available at the end of the article
}

It is generally accepted that the occurrences of undercut and humping bead have similar mechanism. Some theories had been proposed to reveal this reason. Mills and Keene [1] suggested that the presences of humping bead and undercut attribute to the Marangoni force created in molten pool, which is based on the observation that humping bead is affected by sulfur content in the weld metal. Paton et al. [2] believed that, there exists a pressure balance between the welding arc and the molten metal. Arc pressure increases with the welding current to the point of an imbalance in forces and the defects begin to form. A supercritical flow model was proposed by Yamamoto and Shimada [3]. Under conditions of high current and welding speed, weld depression forms because of the high arc pressure, and the front of molten pool turns into a thin liquid layer called gouging region followed by a trailing region. Humping bead will occur when the velocity of the thin layer is beyond the critical value for a hydraulic jump. Soderstrom and Mendez [4] modified this model. Humping bead produces when the arc pressure extends the gouging region beyond the heat influence of the arc and premature freezing of the 
thin liquid film occurs. The backfilled trailing region then solidifies. To solve the weld forming problems in high speed TIG welding, depressing the arc pressure is believed a good way. Both hollow tungsten electrode [5] and twin tungsten electrodes $[6,7]$ had been used in this field. Moreover, some kinds of external magnetic fields were also applied by some researchers $[8,9]$ to weaken the backward drag of arc and improve the weld formation in high speed TIG welding. Qin et al. [10] employed an assistant TIG arc to prevent the premature solidification of thin liquid layer and the backward molten metal flow.

In order to enhance the weld penetration of TIG welding, many innovative welding processes had been proposed. CSIRO [11] developed a keyhole mode TIG (K-TIG) welding to realize high current TIG welding. Great efforts were also made to combine the TIG arc heat source with other energy sources, such as laser [12], external magnetic field [13], ultrasonic vibration [14] and another arc heat source [15] to reach the goal of deep depth. Besides these, introducing active elements into the arc-pool coupling system using activating flux or activating gas is believed the most effective way to improve the weld penetration [16], meanwhile the energy cost is greatly decreased. This kind of welding method is collectively referred to as activated TIG welding. More and more researches [17-19] revealed the increase of weld depth contributes to either the arc constriction or the reverse of Marangoni convection in the molten pool surface. Both of them can make the arc heat more effectively transferred to the bottom of molten pool.

Brushing flux on the weld surface is the common way to introduce active elements. According to the variable properties of base metal and activating fluxes, several brushing methods [20-22] were put forward to welding different metal. Among these, the method called Activating flux TIG (A-TIG) welding pre-coating flux on the whole weld surface is the most deeply investigated and widely applied in industrial fabrication. To overcome the shortcoming of restricting weld efficiency and affecting the weld quality resulting from the flux coating process above-mentioned, Huang et al. [23, 24] creatively transferred the activating flux into the arc-pool coupling system through the argon shielding gas of TIG welding.

Another way to introduce activating elements is utilizing gas containing active elements. For ferroalloys, activating elements, such as oxygen and sulfur, can decrease the surface tension of molten metal and reverse Marangoni convection flow, eventually obtain a much deeper weld depth. Accordingly, Heiple and Burgardt [25] added a small amount of $\mathrm{SO}_{2}$ into the argon shielding gas and obtained obviously increased weld penetration. Fujii et al. $[26,27]$ developed an Advanced A-TIG (AA-TIG) welding method to prevent oxidation consumption of the tungsten electrode by using a double shielding gas torch instead of the normal TIG welding torch. An assisted TIG arc with $\mathrm{Ar}+\mathrm{O}_{2}$ or $\mathrm{Ar}+\mathrm{CO}_{2}$ mixed shielding gas and low current was used by Fan and Huang [28-30] to form a thin oxide layer to introduce oxygen element before the common TIG welding and dramatically increase weld penetration in the end. A similar thin oxide film was produced using laser irradiation with oxygen gas by Mizutani and Katayama [31].

In this study, a novel variation of activated TIG welding method called Gas Pool Coupled Activating TIG (GPCATIG) welding with coupling arc electrode is put forward to actualize a TIG welding process simultaneously with deep penetration and high welding speed. This process is based on a specialized double layers gas shielded TIG welding method named GPCA-TIG welding [32] developed in-house. The inner inert shielding gas is to prevent tungsten electrode from oxidation. The outer pure/mixing gas contains oxygen and/or nitrogen elements. Oxygen is introduced to dramatically increase weld depth, while nitrogen to improve weld quality. The relative position between the outer and inner convergent nozzles, simplified as a variable $h$ named coupling degree, can be changed to adjust the coupled area and position between the outer activating gas and molten pool surface and control the weld shape and properties. The kind of coupling arc electrode was developed in-house to decrease arc pressure by cutting the tip of normal solid clubbed tungsten into four identical parts. Through analyzing the arc pressure and the influences of welding parameter on weld appearance, the feasibility of this process is discussed in this paper.

\section{Experimental}

The GPCA-TIG welding method and the coupling arc electrode are shown in Figures 1 and 2. In order to investigate the arc pressure and weld shape, a torch [33] developed by ourselves as shown in Figure 3 is utilized to produce a GPCA-TIG welding arc with coupling arc electrode. The inner and outer gases are respectively argon and oxygen both with purity of $99.9 \%$. A W-2\% $\mathrm{Ce}_{2} \mathrm{O}_{3}$ electrode is employed with three levels of tungsten electrode diameter $d_{e}=3.2 \mathrm{~mm}, 4.0 \mathrm{~mm}$ and $5.0 \mathrm{~mm}$. The value of coupling degree $h$ is defined as shown in Figure 4 . When the positions of the outer and inner nozzle tips are aligned, the $h$ value is zero. The positive value indicates the position of outer nozzle tip is higher than that of inner nozzle, while the negative value represents converse position relationship.

In the interest of measurements of arc pressure distribution along the anode surface, static keyhole method was utilized. As seen in Figure 5, the anode is water cooled copper plate. Through a pressure tube of a $0.8 \mathrm{~mm}$ 


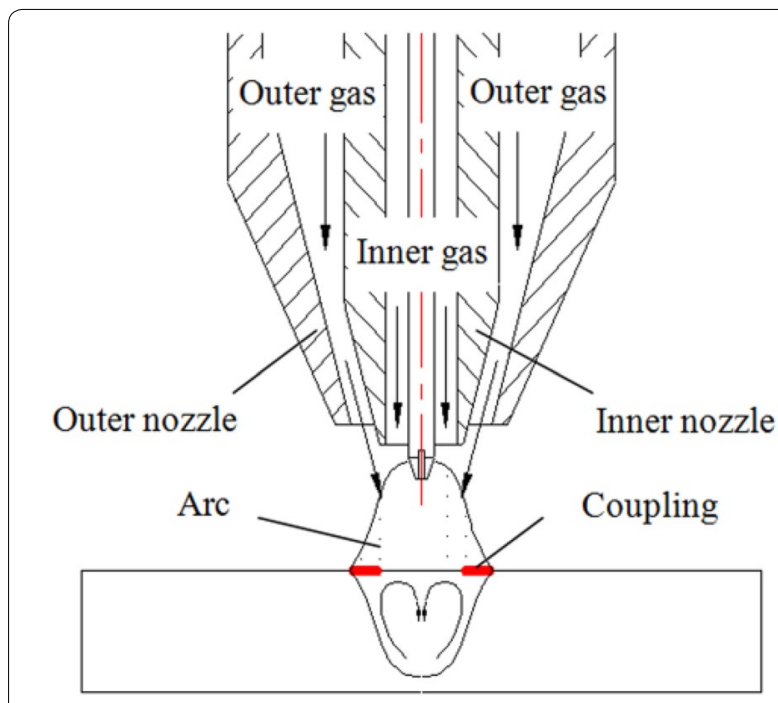

Figure 1 Schematic of GPCA-TIG welding with coupling arc electrode

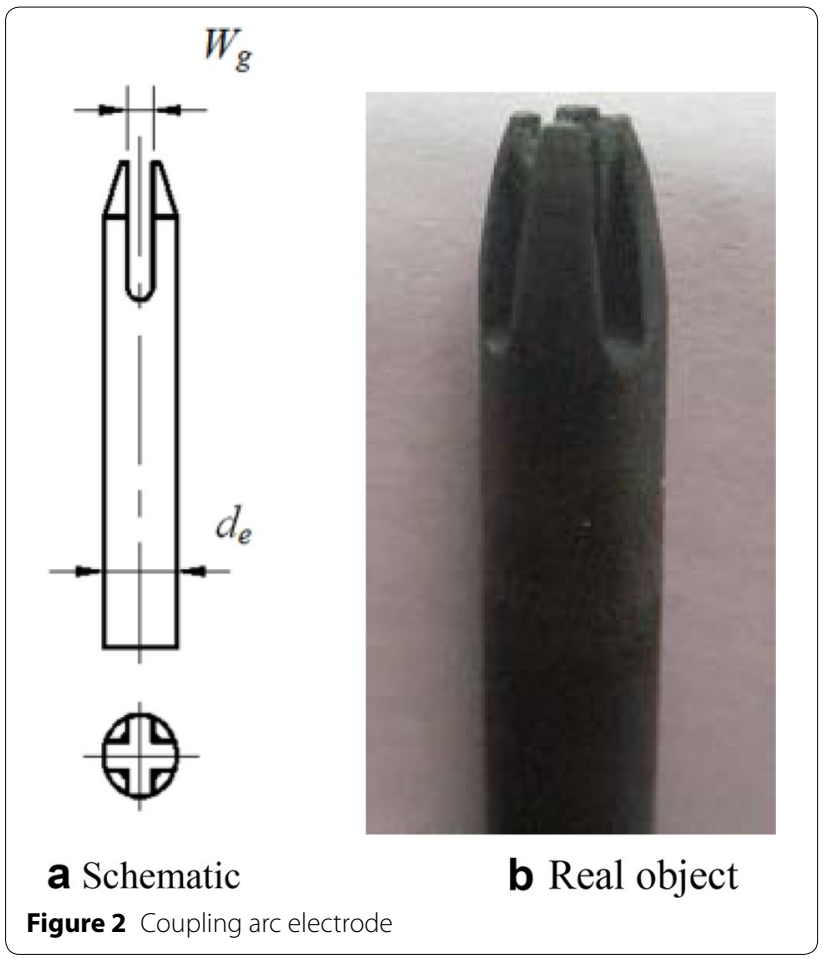

inner diameter, the arc pressure is conducted to a pressure sensor and shifted into electric signal. In the end, a computer is used to collect the electric signal from a sampling resistance and obtain the arc pressure value required.

Due to the aimed application field of large current and high speed welding, a tungsten electrode with diameter $d_{e}$ of $5 \mathrm{~mm}$ and gap width $W_{g}$ of $1.4 \mathrm{~mm}$ was selected to performance a series of bead-on-plate welding experiments on $5 \mathrm{~mm}$ thickness plate of SUS304 stainless steel. The basic welding specifications are current $400 \mathrm{~A}$, travel speed $700 \mathrm{~mm} / \mathrm{min}$, electrode extension $4 \mathrm{~mm}$, arc length $6 \mathrm{~mm}$, flow rate of inner argon $13 \mathrm{~L} / \mathrm{min}$, flow rate of outer oxygen $6 \mathrm{~L} / \mathrm{min}$, coupling degree 0 . Comparison of weld shapes between conventional TIG welding, TIG welding with coupling arc tungsten electrode and GPCATIG welding with coupling arc tungsten electrode were made. During this process, the weld shape is characterized with the weld depth $D$, weld width $W$ and the undercut $U$. The value of undercut $U$ is referred as the larger surface depression in the weld brim. Based on these, the influences of major welding parameters on weld shape were investigated.

\section{Arc Pressure}

In order to determine the symmetrical characteristics of GPCA-TIG arc, the arc pressures in two directions presented in Figure 6(a) were gauged. As shown in Figure 6(b), despite the existence of the orthogonal gaps at the electrode tip as seen in Figure 2, difference of arc pressure between along the gap $\left(0^{\circ}\right.$ direction) and through the solid part of the electrode ( $45^{\circ}$ direction) hardly presents for different welding currents. This indicates that this welding process can be performed in any direction and has extensive adaptability.

Based on the experiments mentioned above, the TIG arc pressure distributions with normal solid tungsten electrode and the coupling arc tungsten electrode were compared in Figure 7. Obviously, the arc pressures with coupling arc electrode are much lower than those with normal electrode. Although quite a few researchers had employed hollow tungsten or twin tungsten electrodes to effectively reduce the arc pressure, the coupling arc electrode as shown in Figure 2 is easier to manufacture as compared with hollow tungsten electrode [5]. The welding torch has more compact structure as compared with twin electrodes [6, 7].

In contrast with the arc appearance of normal electrode as given in Figure 8, it is found that the arc cathode radius obviously broadens. In an arc plasma, there exists electromagnetic force (also called Lorentz force) perpendicular to the current line because of the interaction of electric field and the self-induced magnetic field. The broadened cathode zone will decrease the current density $J$ and increase the directional angle $\beta$ as shown in Figure 9, which lead to a decreased axial component of electromagnetic force directing to the anode plate surface and a lowered arc pressure according to the formula of axial arc force given in Eq. (1):

$$
F_{a}=|\boldsymbol{J} \times \boldsymbol{B}| \cos \beta,
$$




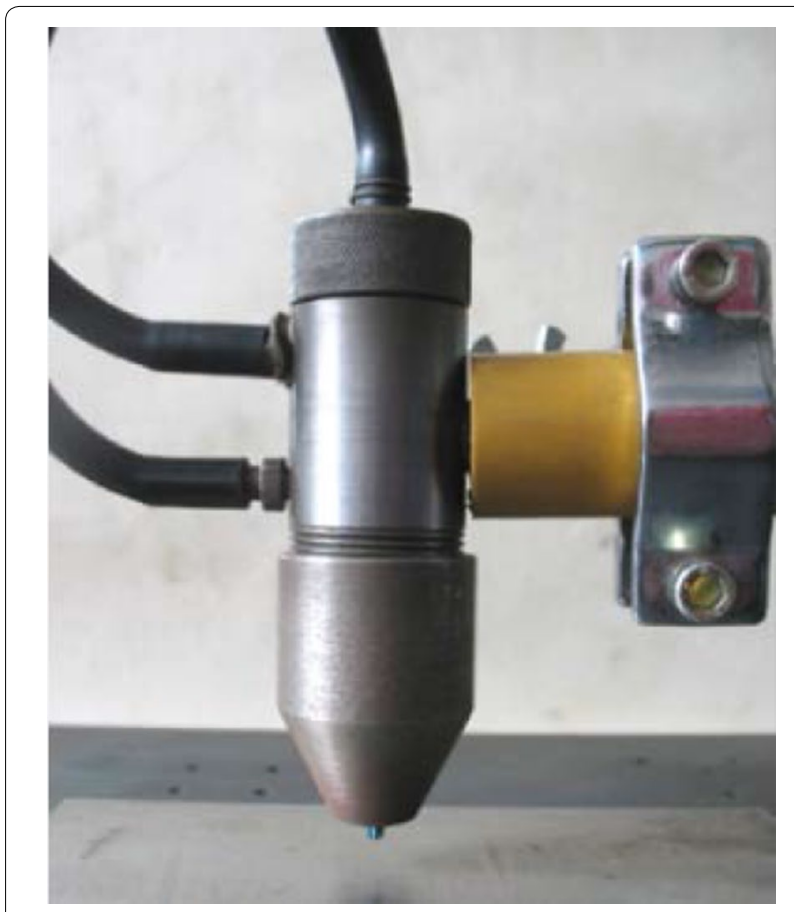

Figure 3 GPCA-TIG welding torch

where $F_{\alpha}$ is the axial electromagnetic force, $\boldsymbol{J}$ is the current density vector, $\boldsymbol{B}$ is the magnetic induction intensity vector, $\beta$ is the directional angle.

It is also found in Figure 7 that the arc pressures decrease with the increases of the electrode diameter and gap width. These phenomena are similar to those in twin tungsten electrodes TIG welding [34, 35].

\section{Weld Appearance of High Speed Welding}

\subsection{Comparison with Different Welding Process}

Comparison of weld shapes between the normal TIG welding, TIG welding with coupling arc electrode and the GPCA-TIG welding with coupling arc electrode were made. As shown in Figure 10, the normal TIG welding, that is to say when the normal GPCA-TIG welding is absent from outer gas, produces heavy humping bead owing to the relative high travel speed. If the normal solid electrode is replaced by the coupling arc electrode, the humping bead is eliminated and only a few undercuts present. As mentioned above, the coupling arc electrode can produce lower arc pressure resulting in much shallower depression of the molten pool. This benefits the disappearance of the humping bead. Then adding outer gas oxygen into the outer gas path of the GPCATIG welding torch, neither the humping bead nor the undercut exists. At the same time, comparing with TIG welding methods not only with normal electrode but also with coupling electrode, the weld penetration of 2.9 mm of GPCA-TIG welding with coupling arc electrode is significantly improved from the corresponding values of $2.6 \mathrm{~mm}$ and $2.1 \mathrm{~mm}$ respectively. As a kind of activating element for iron alloy, the addition of oxygen into the weld pool will decrease the surface tension of the molten metal and improve the wettability between liquid molten metal and solid base metal. Meanwhile, the active oxygen element introduced will also change the surface tension temperature coefficient and enhance the forward fluid flow of molten metal in the rear region. These two effects resulting from the introduction of oxygen help humping bead and/or undercut be got over. Moreover, on the basis of theory of oxygen changing surface tension temperature coefficient, the flow reverse in the weld pool will make more arc heat transferred to the bottom of molten pool and obtain a much deeper penetration. It can be concluded from these experimental results, the GPCATIG welding method with coupling arc electrode is much

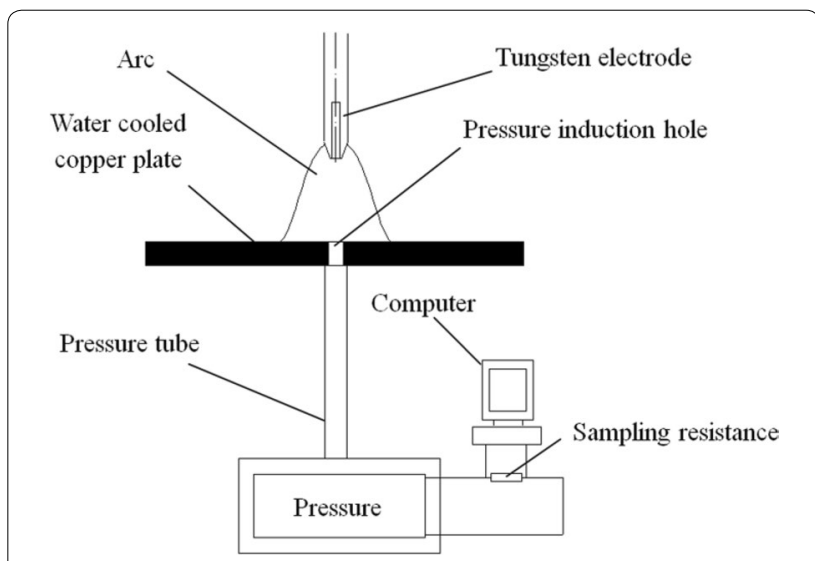

Figure 5 Schematic of arc pressure acquisition system

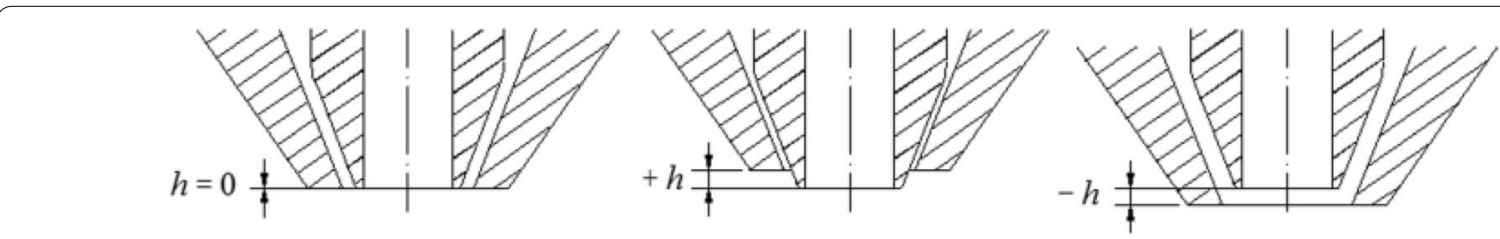

Figure 4 Relative position between the outer and inner nozzles 
more suitable to perform in the high productivity fields requiring high welding speed and deep weld depth.

\subsection{Effects of Welding Parameters}

Figure 11 presents the influences of major welding parameters on weld appearance. With the increase of travel speed, the heat input per unit weld length reduces, resulting in weld depth and width simultaneously decreasing. The effect on undercut is much complicated. When the travel speed is lower $(v \leq 700 \mathrm{~mm} / \mathrm{min})$, there is no undercut presenting. Then the undercut increases. However, with the travel speed further increasing $(v \geq 900 \mathrm{~mm} / \mathrm{min})$, owing to the reductions of the heat input per unit weld length and the weld volume molten, the weakened depression of molten pool surface results in gradually decreased weld undercut. For other welding parameters, including the normal ones of TIG welding, such as arc length and election extension as well as the specific ones of GPCA-TIG welding, such as flowrate of oxygen and coupling degree, all of them have minor influence on the weld depth and width. Concerning the effects on weld undercut, both arc length and electrode extension have a weaken influences. For oxygen flowrate

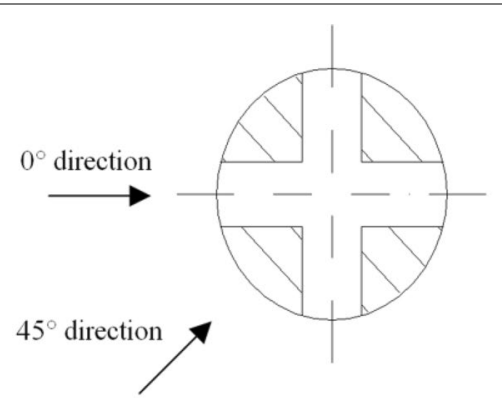

a Schematic of arc pressure measurement direction

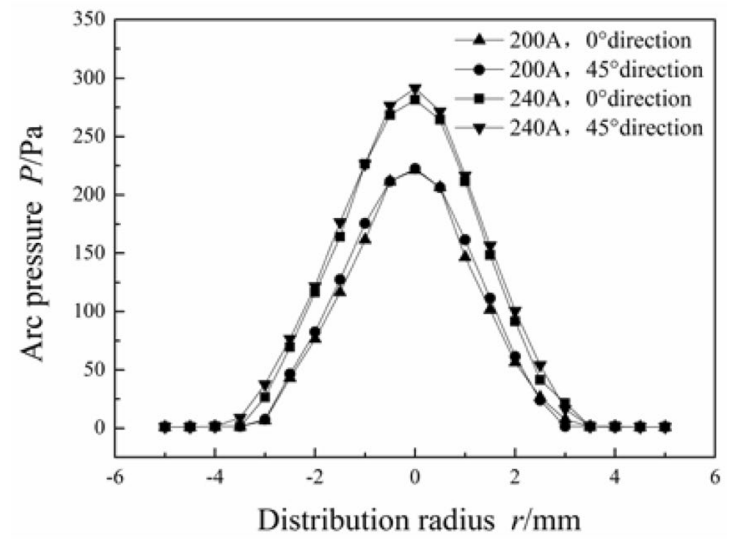

b Arc pressure distribution

Figure 6 Arc pressures in different direction and coupling degree, their effects on undercut are the same. When the oxygen flow rate and coupling degree increase, more and more oxygen comes into the welding arc and pool resulting in a constricted arc and increased oxygen content in the pool. These will make the arc pressure increase and the surface tension of the molten pool decrease. The mechanical balance at the surface of molten pool is broken. Because these kinds of effects of oxygen introducing are relatively weaker, the enhancement of weld surface depression is not obvious. Meanwhile, the increase of oxygen content in molten pool makes the forward fluid metal flow of the rear weld pool first enhance then weaken, which matches the dependence of surface tension temperature coefficient on oxygen content as shown in Figure 12 based on the formula given in Eq. (2) proposed by Sahoo et al. [36]:

$\frac{\partial \gamma}{\partial T}=-A-R \Gamma_{s} \ln \left(1+K_{\text {seg }} a_{O}\right)-\frac{K_{\text {seg }} a_{O}}{1+K_{\text {seg }} a_{O}} \frac{\Gamma_{s} \Delta H^{0}}{T}$,

$K_{\text {seg }}=k_{1} \exp \left(\frac{-\Delta H^{0}}{R T}\right)$,

where $\partial \gamma / \partial T$ is the surface tension temperature coefficient, $A$ is the negative of $\partial \gamma / \partial T$ for pure metals, $\Gamma_{S}$ is the surface excess at saturation, $R$ is the gas constant, Kseg is the adsorption coefficient, $k_{1}$ is the constant related to entropy of segregation, $\Delta H^{0}$ is the standard heat of absorption, $a_{O}$ is the activity of oxygen. Consequently, the influences of both oxygen flow rate and coupling degree on the weld undercut exhibit a tendency of first decreasing then increasing.

\section{Conclusions}

1. The distributions of arc pressure in different directions were evaluated. The results indicate the welding torch developed in-house has good structure symmetry and the GPCA-TIG arc can be used to weld in any direction.

2. When a normal solid tungsten electrode is substituted by a coupling arc electrode, the arc pressure produced is decreased dramatically. With the increases of the electrode diameter and gap width, the arc pressure decreases.

3. In the GPCA-TIG welding method with coupling arc electrode, both the substitution of coupling arc electrode and the introduction of outer oxygen can reduce the possibilities of producing humping bead and undercut. This process has the capable of realizing high travel speed and deep penetration welding.

4. The effects of main welding parameters on weld shape were evaluated. Within the experimental 


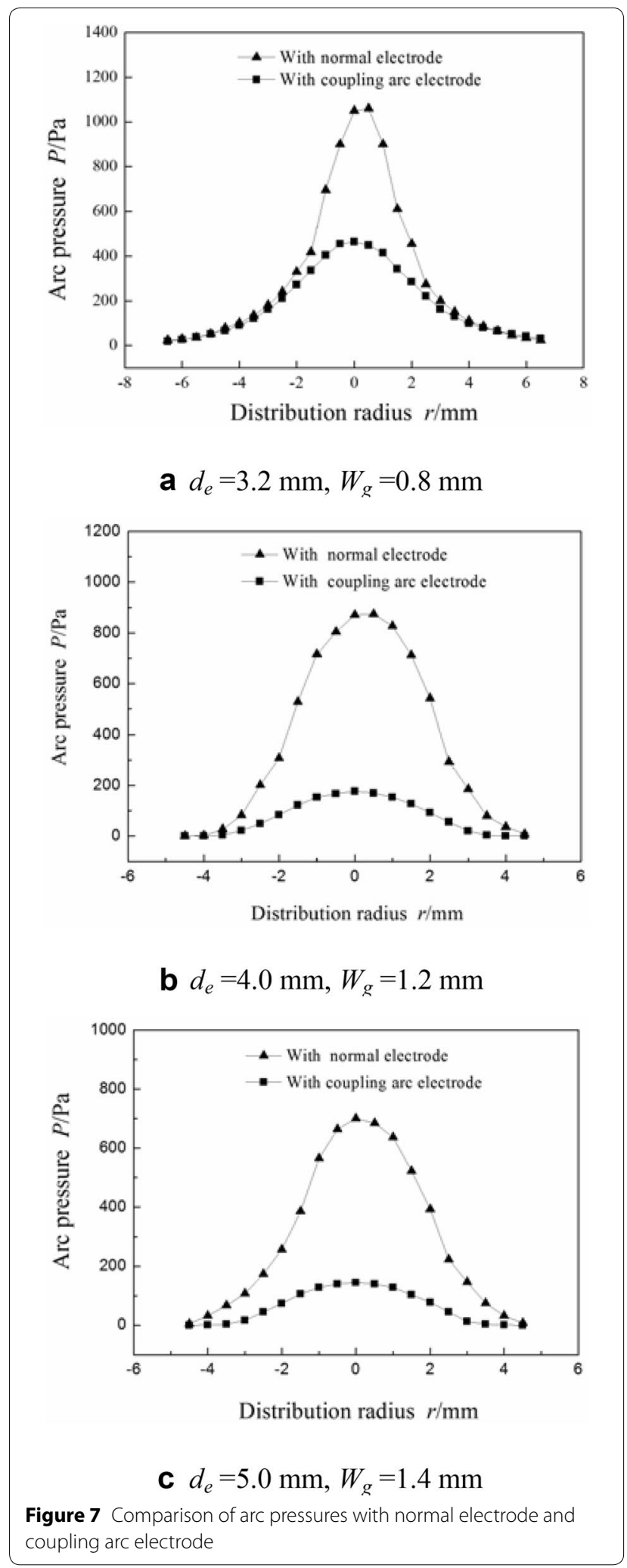

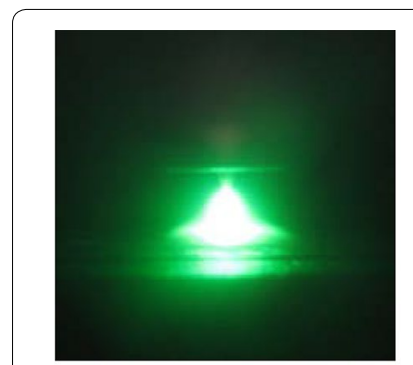

a With normal electrode

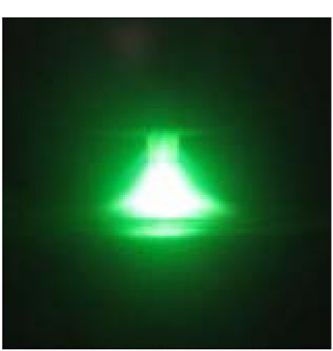

b With coupling arc electrode

Figure 8 Comparison of arc shapes with normal electrode and coupling arc electrode

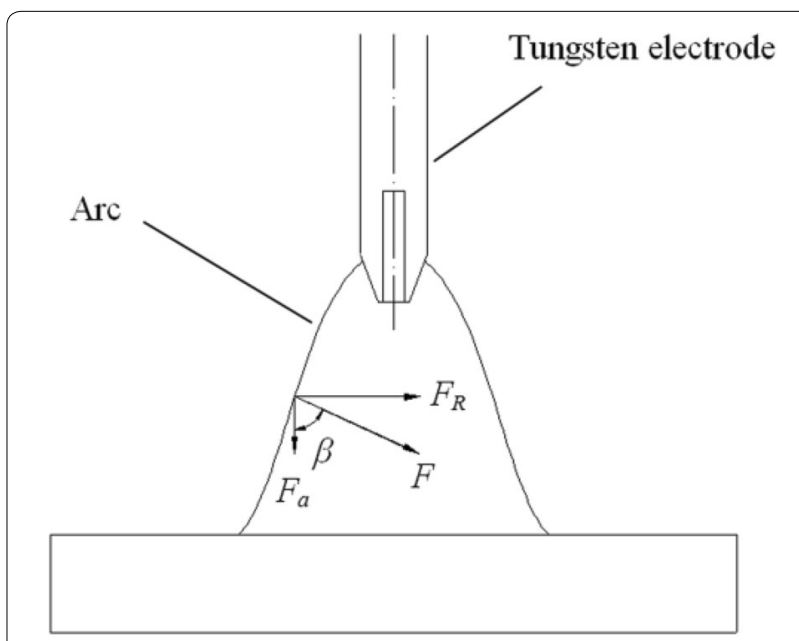

Figure 9 Axial arc pressure analysis

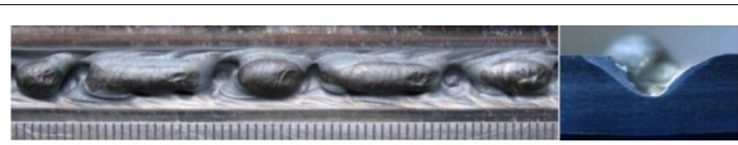

a TIG welding with normal electrode

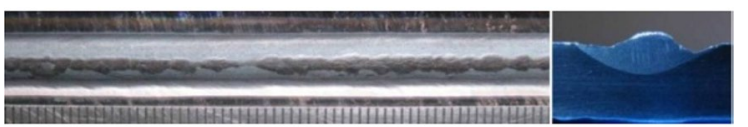

b TIG welding with coupling arc electrode

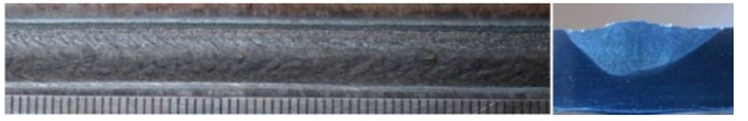

C GPCA-TIG welding with coupling arc electrode Figure 10 Comparison of weld shape 


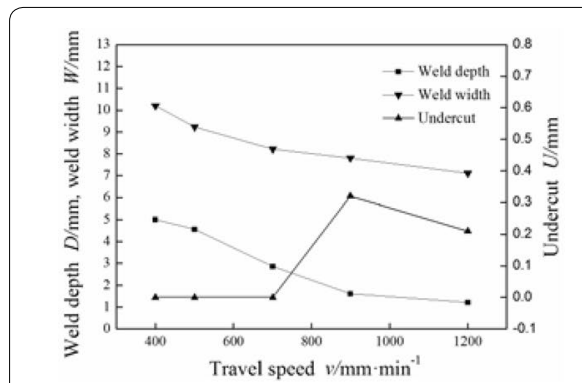

a Travel speed

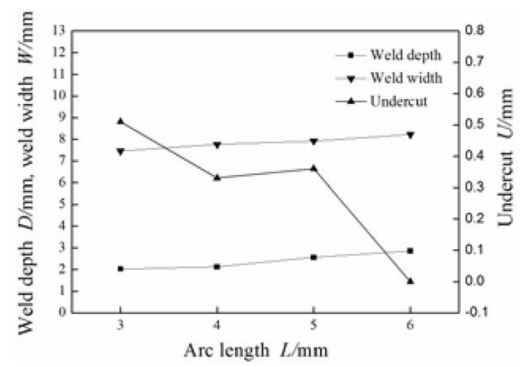

b Arc length

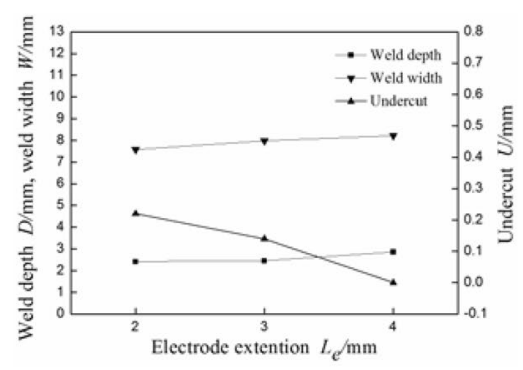

C Electrode extension

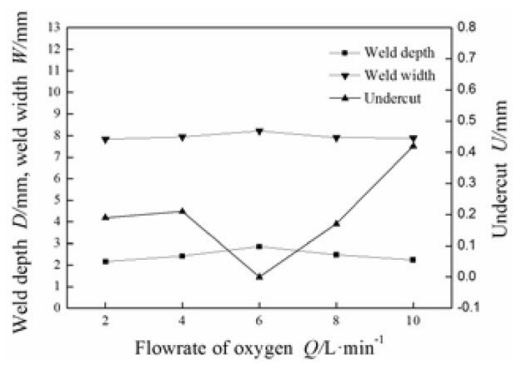

d Flowrate of oxygen

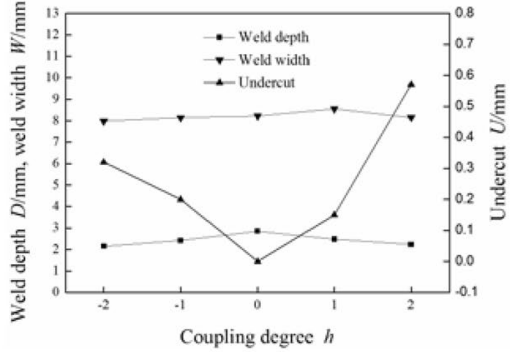

e Coupling degree

Figure 11 Effects of welding parameters on the GPCA-TIG weld shape

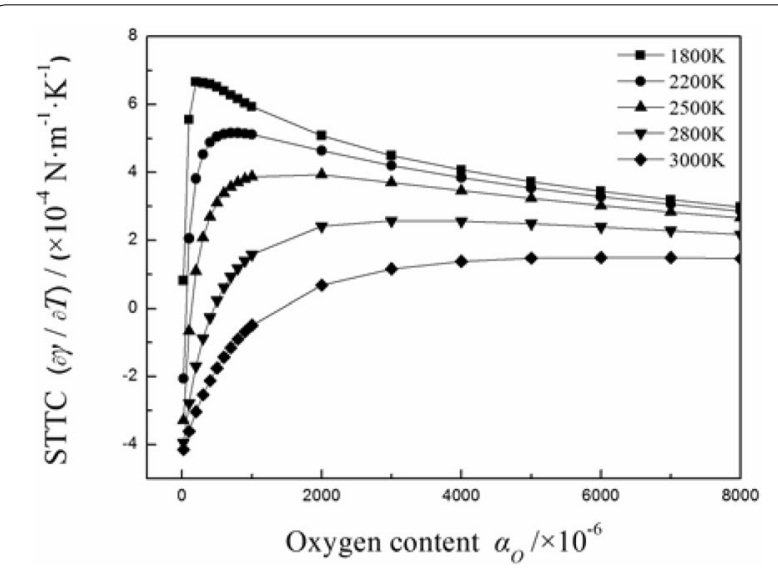

Figure 12 Dependence of surface tension temperature coefficient on oxygen content

range, travel speed compared with other specifications exhibits much more obvious influence on weld depth and width. Concerning the weld undercut, travel speed, oxygen flowrate and coupling degree present complicated and prominent influences, while arc length and electrode extension have weaken straight-forward effects.

\section{Authors' Contributions}

$\mathrm{YH}$ was in charge of the whole trial; $\mathrm{YH}$ wrote the manuscript; R-LL and $\mathrm{Y}$-ZH assisted with sampling and laboratory analyses. All authors read and approved the final manuscript.

\section{Author Details}

${ }^{1}$ State Key Laboratory of Advanced Processing and Recycling of Non-ferrous Metals, Lanzhou University of Technology, Lanzhou 730050, China. ${ }^{2}$ Department of Aviation Manufacture Engineering, Chengdu Aeronautic Polytechnic, Chengdu 610100, China. ${ }^{3}$ Technology Center, Great Wall Motor Company Limited, Baoding 071000, China.

\section{Authors' Information}

Yong Huang, born in 1972, is currently a professor at State Key Laboratory of Advanced Processing and Recycling of Non-ferrous Metals, Lanzhou University of Technology, China. He received his PhD degree from Lanzhou University of Technology, China, in 2007. His research interests include advanced welding technology, welding physics and welding numerical analysis.

Rui-Lin Liu, born in 1987, is currently a teaching assistant at Chengdu Aeronautic Polytechnic, China. She received her master degree on material processing engineering from Lanzhou University of Technology, China, in 2012.

Yan-Zhao Hao, born in 1983, is currently an assistant engineer at Technology Center of Great Wall Motor Company Ltd, China. He received his master degree on material processing engineering from Lanzhou University of Technology, China, in 2013.

\section{Competing Interests}

The authors declare that they have no competing interests.

\section{Funding}

Supported by National Natural Science Foundation of China (Grant No. 51265029).

\section{Publisher's Note}

Springer Nature remains neutral with regard to jurisdictional claims in published maps and institutional affiliations.

Received: 19 October 2016 Accepted: 9 November 2018

Published online: 21 November 2018 


\section{References}

[1] KC Mills, B J Keene. Factors affecting variable weld penetration. International Materials Reviews, 1990, 35(4): 185-216.

[2] E O Paton, S L Mandel'berg, B G Sidorenko. Certain special features of the formation of welds made at high speeds. Automatic Welding USSR, 1971, 24(8): 1-6.

[3] TYamamoto, W Shimada. A study on bead formation in high speed TIG arc welding at low gas pressure. Proceedings of 2 nd International Symposium JWS on Advanced Welding Technology, Osaka, Japan, Aug. 25-27 1975, paper 2-2-(10).

[4] E Soderstrom, P Mendez. Humping mechanisms present in high speed welding. Science and Technology of Welding and Joining, 2006, 11(5): 572-579.

[5] N Yamauchi, TTaka, M Oh-i. Development and application of high current TIG process (SHOLTA welding process). Sumitomo Search, 1981, 25: 87-100.

[6] K Kobayashi, Y Nishimura, T lijima, et al. Practical application of high efficiency twin-arc TIG welding method (SEDAR-TIG) for PCLNG storage tank. Welding in the World, 2004, 48(7): 35-39.

[7] Y Ogino, Y Hirata, K Nomura. Numerical analysis of the heat source characteristics of a two-electrode TIG arc. Journal of Physics. D: Applied Physics, 2011, 44(21): 215202-215208.

[8] Y L Chang, D C Yang, L Wei, et al. Influence of magnetic controlled technology on formation of high-speed TIG welding. Transactions of the China Welding Institution, 2011, 32(3): 49-52. (in Chinese)

[9] K Nomura, Y Ogino, Y Hirata. Shape control of TIG arc plasma by cusp type magnetic field with permanent magnets. Welding International, 2012, 26 (10): 759-764.

[10] G L Qin, X M Meng, B L Fu. High speed tandem gas tungsten arc welding process of thin stainless steel plate. Journal of Materials Processing Technology, 2015, 220: 58-64.

[11] B L Jarvis, N U Ahmed. Development of keyhole mode gas tungsten arc welding process. Science and Technology of Welding and Joining, 2000, 5(1): 1-7.

[12] U Reisgen, I Krivtsun, B Gerhards, et al. Experimental research of hybrid welding processes in combination of gas tungsten arc with $\mathrm{CO}_{2}$ - or Yb:YAG-laser beam. Journal of Laser Applications, 2016, 28(2): 022402-1-5.

[13] C Kou. The effect on TIG welding arc characteristic with different longitudinal magnetic frequency. Shenyang: Shenyang University of Technology, 2015. (in Chinese)

[14] Q J Sun, S B Lin, C L Yang. Penetration increase of AISI 304 using ultrasonic assisted tungsten inert gas welding. Science and Technology of Welding and Joining, 2009, 14(8): 765-767.

[15] Y M Zhang, S B Zhang. Double-sided arc welding increase weld joint penetration. Welding Journal, 1998, 77(6): 57-61.

[16] R S Vidyarthy, D K Dwivedi. Activating flux tungsten inert gas welding for enhanced weld penetration. Journal of Manufacturing Processes, 2016, 638(22): 211-218.

[17] R H Zhang, J L Pan, S Kakayama. The mechanisms of penetration increase in A-TIG welding. Frontiers of Materials Science, 2011, 5(2): 109-118.

[18] D S Howse, W Lucas. Investigation into arc constriction by active fluxes for tungsten inert gas welding. Science and Technology of Welding and Joining, 2000, 5(3): 189-193.
[19] Y Huang, D Fan, Q H Fan. Study of mechanism of activating flux increasing weld penetration of AC A-TIG welding for aluminum alloy. Journal of Mechanical Engineering, 2006, 42(5): 45-49. (in Chinese)

[20] A G Simonik. Influence of halides on penetration effect in argon-arc welding of titanium alloys. Welding Production, 1974, 21(3): 81-82.

[21] S Sire, S Marya. New perspectives in TIG welding of aluminium through flux application FBTIG process. Proceedings of 7 th International Symposium on Today and Tomorrow in Science and Technology of Welding and Joining, Kobe, Japan, November 20-22, 2001: 113-118.

[22] Y Huang, D Fan, F Shao. Alternative current flux zoned tungsten inert gas welding process for aluminium alloys. Science and Technology of Welding and Joining, 2012, 17(2): 122-127.

[23] Y Huang, T LI, Y L Wang. Gas transfer flux activating TIG welding process for aluminum alloy. Transactions of the China Welding Institution, 2014, 35(1): 101-104. (in Chinese)

[24] Y Huang, T Li. A Tungsten Inert Gas welding with gas transferring activating flux: CN, 201210242233.3. 2012-10-24. (in Chinese)

[25] C R Heiple, P Burgardt. Effects of $\mathrm{SO}_{2}$ shielding gas addition on GTA weld shape. Welding Journal, 1985, 64(6): 159-162.

[26] H Fujiii, T Sato, S P Lu, et al. Development of an advanced A-TIG (AA-TIG) welding method by control of Marangoni convection. Materials Science and Engineering A, 2008, 495(1-2): 296-303.

[27] Y Zou, R Ueji, H Fujii. Effect of oxygen on weld shape and crystallographic orientation of duplex stainless steel weld using advanced A-TIG (AA-TIG) welding method. Materials Characterization, 2014, 91(5): 42-49.

[28] D Fan, T Lin, Y Huang, et al. Arc assisted activating TIG welding process. Transactions of the China Welding Institution, 2008, 29(12): 1-4, 32. (in (hinese)

[29] Y Huang, D Fan, T Lin, et al. Arc assisted activating TIG welding process for stainless steels. Transactions of the China Welding Institution, 2009, 30 (10): 1-4. (in Chinese)

[30] Y Huang, D Fan, T Lin, et al. Arc assisted activating TIG welding process for stainless steels. Journal of Mechanical Engineering, 2012, 48(8): 68-72. (in Chinese)

[31] M Mizutani, S Katayama. TIG weld penetration improvement by laseractivated process with oxygen. Welding in the World, 2012, 56(1-2): 21-29.

[32] Y Huang, R L Liu, D Fan, et al. Gas pool coupled activating TIG welding method. Transactions of the China Welding Institution, 2012, 33(9): 13-16. (in Chinese)

[33] Y Huang, Y Z Hao, R L Liu. A water cooled welding torch for Gas Pool Coupled Activating TIG welding process: CN, 201110393665.X. 2014-08-08. (in Chinese)

[34] XX Wang, D Fan, J K Huang, et al. Numerical simulation of coupled arc in double electrode tungsten inert gas welding. Acta Physica Sinica, 2013, 62(22): 1-10. (in Chinese)

[35] Y Huang, XX Wang, HY Qu, et al. Effects of arc parameters on arc anode current density of coupling AA-TIG arc. Transactions of the China Welding Institution, 2014, 35(2): 5-9. (in Chinese)

[36] P Sahoo, T Debroy, M J McNallan. Surface tension of binary metal surface active solute systems under conditions relevant to welding metallurgy. Metallurgical Transactions B, 1988, 19(3): 483-491.

\section{Submit your manuscript to a SpringerOpen ${ }^{\circ}$ journal and benefit from:}

- Convenient online submission

- Rigorous peer review

- Open access: articles freely available online

- High visibility within the field

Retaining the copyright to your article

Submit your next manuscript at springeropen.com 